\title{
ENSAIO DE ADSORÇÃO DA PLANTA INVASORA CAPIM- ANNONI-2 COM O CORANTE AZUL DE METILENO
}

\author{
N. O. CORAL ${ }^{1}$, R. B. RIBEIRO ${ }^{1}$, E. M. SILVA ${ }^{1}$, L. B. ANDRADE ${ }^{1}$ e P. H. PALHARIM ${ }^{1}$. \\ ${ }^{1}$ Universidade Federal do Pampa, Departamento de Engenharia Química \\ E-mail para contato: nicoly.coral@gmail.com
}

\begin{abstract}
RESUMO - A indústria têxtil emprega uma série de corantes sintéticos para o tingimento de fibras têxteis, sendo lançados no seu efluente líquido. Métodos convencionais de tratamento de efluentes apresentam-se, em geral, com alto custo, sendo necessária a busca por diferentes processos. A adsorção é um processo estudado em virtude de ser uma boa opção para o tratamento de efluentes líquidos com baixos custos, utilizando-se materiais alternativos. Dessa forma, estudou-se a capacidade de adsorção do corante azul de metileno (AM) em capim-annoni-2 em ensaios batelada, onde se variou a concentração do corante, a massa de adsorvente e o pH da solução. Por meio dos resultados obtidos, pode-se concluir que a concentração de AM na solução e a massa de adsorvente que melhor responderam às condições dos ensaios, foram de $0,25 \mathrm{~g} / \mathrm{L}$ e $1,0 \mathrm{~g}$, respectivamente. Ademais, observou-se que as variações de $\mathrm{pH}$ possuem baixa influência na adsorção de $\mathrm{AM}$ em capim-annoni-2 e que o mesmo possui capacidade adsortiva.
\end{abstract}

\section{INTRODUÇÃO}

\subsection{Capim-Annoni-2 (Eragrostis plana Nees)}

A espécie invasora capim-annoni-2 (Eragrostis plana Nees), proveniente do sul do continente africano (REIS, 1993), é considerada uma praga devido seu poder de infestação em pastagens. Esta gramínea se adapta a qualquer tipo de solo e apresenta crescimento acelerado e descontrolado, desenvolvendo-se com facilidade em solos com baixa fertilidade. Desde sua inserção nos biomas gaúchos na década de 50, estima-se que cerca de $20 \%$ da vegetação campestre do Rio Grande do Sul esteja infestada por este capim (Goulart et al. 2009).

Segundo Medeiros et al. (2007), é inviável sua utilização como alimento na pecuária, uma vez que apresenta baixos teores de proteína e digestibilidade inferior a 55\%. Estas espécies daninhas também causam enormes prejuízos à agricultura, interferindo no desenvolvimento de plantas que são de interesse humano, alterando significativamente a qualidade da colheita e do produto final (KLEIN, 2015 apud SILVA; COELHO; MEDEIROS, 2008; DASTAN et al., 2014).

\subsection{Adsorção}

A indústria têxtil é um setor em constante ascensão e é visível a poluição gerada pelos seus efluentes, já que cerca de 20 toneladas/ano de corantes são consumidos no Brasil e $20 \%$ 
são descartados como efluentes segundo DALLAGO et al. (2005). A água é um elemento essencial no processo de produção, onde sua maior proporção é utilizada no tingimento (52\%), seguido pelos processos de preparação $(41 \%)$, refrigeração $(6 \%)$ e acabamento $(1 \%)$ (KIMURA, 2001).

Diferentes métodos têm sido desenvolvidos com o intuito de tratar os efluentes provenientes de indústrias têxteis que poluem visualmente a água, alteram os ciclos biológicos como a fotossíntese e a repodução dos animais marinhos, além de possuírem compostos carcinogênicos e mutagênicos em sua composição (CÓRDOVA; DA SILVA E CÓRDOVA, 2010). Dentre estes métodos, um dos mais populares é a adsorção.

A adsorção é um fenômeno de superfície no qual o soluto é removido de uma fase e acumulado na superfície da segunda fase. O material inicialmente adsorvido é o adsorvato, e o material onde se faz a remoção é chamado de adsorvente (KOUYOUMDJIEV, 1992 apud PERUZZO, 2003, p. 14). De acordo com Nascimento (2014), a adsorção possui diversos fatores que influenciam o processo como a área superficial, as propriedades do adsorvente e do adsorvato, a temperatura do sistema, natureza do solvente e o $\mathrm{pH}$ do meio.

O presente trabalho teve como finalidade analisar a capacidade de adsorção do corante azul de metileno pela planta capim-annoni-2 em ensaio batelada em diferentes condições, variando-se as concentrações do adsorvato, a massa presente do adsorvente e o pH do meio.

\section{MATERIAL E MÉTODOS}

\subsection{Preparo da Amostra}

A coleta das folhas de capim-annoni-2 foi realizada no Campus da UNIPAMPA Bagé/RS, no outono. As touceiras da planta foram coletadas manualmente, suas folhas separadas e submetidas à limpeza, as quais foram levadas à estufa em temperatura de $30^{\circ} \mathrm{C}$ por $72 \mathrm{~h}$. Colheu-se as folhas semanalmente de forma que as análises realizadas apresentassem o mesmo tempo de preparo. Após a secagem as folhas foram trituradas em moinho de facas tipo Croton da marca Marconi, modelo MA-580, e separada a fração de mesh 60 por ensaio granulométrico, em agitador magnético por período de 15 minutos na agitação de nível 2 do equipamento.

\subsection{Análises de Adsorção}

As soluções foram previamente preparadas a partir de AM em pó, pesando a quantidade necessária em balança analítica e diluindo em balão volumétrico de 1L. Após o preparo, as soluções foram armazenadas em frascos âmbar para evitar a decomposição do adsorvato.

Para o estudo da influência da concentração do adsorvato, inicialmente fixou-se o valor da massa de adsorvente no valor de 1,0 g de capim moído. Assim, variou-se a concentração do corante em um intervalo de $0,10,0,25$ e $0,50 \mathrm{~g} / \mathrm{L}$. A seguir, adicionou-se estas frações de massa em erlenmeyers com $50 \mathrm{~mL}$ das soluções e agitou-se em mesa agitadora da marca Nova Ética, modelo 109/1, na rotação de 100 rpm, em período de 40 minutos com duplicata. 
Para a análise da influência da massa do adsorvente, pesou-se 3 diferentes valores de massas de capim $(0,5,1,0$ e 1,5 g), as quais foram colocadas à solução de azul de metileno na concentração de melhor resultado no ensaio anterior. Em seguida, seguiu-se o mesmo procedimento utilizado na análise precedente para a etapa de agitação.

Fixando-se os parâmetros de massa do adsorvente e concentração do corante que apresentaram as melhores condições nos ensaios anteriores, fez-se a análise da influência do $\mathrm{pH}$, ajustado esse com a adição de $\mathrm{HCl}$ ou $\mathrm{NaOH}$ para as condições de $\mathrm{pH} 4,7$ e 10. Em sequência, repetiu-se o procedimento já citado para a análises de remoção acima.

Após os ensaios de adsorção, as amostras foram centrifugadas em centrífuga de copos da marca Quimis, modelo Q222TM, com rotação de 3000 rpm, durante 10 minutos e levadas ao espectrofotômetro da marca Equilam, modelo UV755B. Por meio das absorbâncias, lidas na faixa de $645 \mathrm{~nm}$, quantificou-se a concentração de azul de metileno remanescentes nas soluções, sendo obtido o percentual de remoção do corante, através da Equação 1.

$$
\text { Remoção }(\%)=\frac{\text { Concentraçẫo iñicial }^{- \text {Concentraçẫo finnal }}}{\text { Concentraçẩo }} \times 100
$$

A capacidade de adsorção foi obtida através da Equação 2. Onde $q$ é a capacidade de adsorção, $\mathrm{V}$ é o volume da solução e $\mathrm{m}_{\text {capim }}$ é a massa de capim moído utilizada no ensaio.

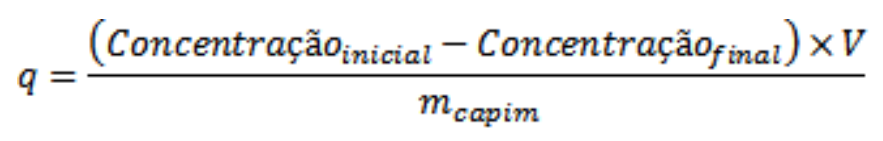

\section{RESULTADOS E DISCUSSÃO}

A influência da concentração inicial de corante AM foi analisada testando-se as concentrações $0,1,0,25$ e $0,5 \mathrm{~g} / \mathrm{L}$ utilizando $1 \mathrm{~g}$ de capim para todos os ensaios. Os resultados estão dispostos na Tabela 1 .

Tabela 1 - Influência da concentração de azul de metileno

\begin{tabular}{|c|c|c|}
\hline Concentração $(\mathrm{g} / \mathrm{L})$ & $q(\mathrm{mg} / \mathrm{g})$ & \% Remoção \\
\hline \hline 0,10 & $4,30 \pm 0,0368$ & $85,80 \pm 0,9470$ \\
\hline 0,25 & $10,47 \pm 0,7696$ & $83,90 \pm 5,9235$ \\
\hline 0,50 & $16,94 \pm 0,9360$ & $67,82 \pm 3,6835$ \\
\hline
\end{tabular}

Com os dados apresentados na Tabela 1 , verifica-se que para a concentração de 0,10 $\mathrm{g} / \mathrm{L}$ ocorre o menor $q$ e o maior percentual de remoção. Este fato pode ser explicado devido à concentração de AM ser muito baixa e a massa de capim atingir o equilíbrio de adsorção aos $85 \%$ do AM em solução. O maior $q$ foi obtido para a concentração de $0,50 \mathrm{~g} / \mathrm{L}$, entretanto, o percentual de remoção para esta condição foi o menor, ou seja, ocorre a saturação do capim como adsorvente em um percentual de remoção inferior. Por fim percebe-se que para a concentração de $0,25 \mathrm{~g} / \mathrm{L}$ obteve-se uma capacidade adsortiva intermediária, porém com um percentual de remoção alto, próximo ao maior obtido. Desta forma, levando-se em 
consideração os custos de reagente, descarte de resíduos gerados e os resultados apresentados pela Tabela 1, escolheu-se a concentração de $0,25 \mathrm{~g} / \mathrm{L}$ para os ensaios seguintes.

O efeito da quantidade de material adsorvente é um estudo necessário em razão de se determinar a quantidade mínima do mesmo a ser utilizada no processo e que apresente valores máximos de adsorção (MITTAL et al., 2010). Os resultados obtidos para a influência da massa do capim no processo de adsorção de AM foram analisados variando-se a massa entre 0,50 e $1,50 \mathrm{~g}$, na concentração de $0,25 \mathrm{~g} / \mathrm{L}$, como apresentado na Tabela 2.

Tabela 2 - Influência da massa de capim na adsorção de azul de metileno

\begin{tabular}{|c|c|c|}
\hline Massa de capim $(\mathrm{g})$ & $q(\mathrm{mg} / \mathrm{g})$ & \% Remoção \\
\hline \hline $0,50 \pm 0,0017$ & $16,77 \pm 0,4256$ & $67,61 \pm 1,5813$ \\
\hline $1,00 \pm 0,2886$ & $11,79 \pm 1,9458$ & $82,74 \pm 1,0676$ \\
\hline $1,50 \pm 0,0032$ & $7,89 \pm 0,9857$ & $85,83 \pm 0,8836$ \\
\hline
\end{tabular}

Por meio da Tabela 2, observou-se que a quantidade adsorvida $q$ diminuiu com o aumento da massa de material adsorvente. Alves (2013) e Clark (2010) também obtiveram o mesmo comportamento nos seus estudos de adsorção de verde malaquita e fenilalanina, respectivamente, por diferentes materiais. Ambos acreditam que o sistema que possui menor massa terá menor quantidade de sítios para a adsorção e, desta forma, há uma maior competição das moléculas de adsorvato por sítios. Logo, a menor quantidade de massa adsorverá, por grama de adsorvente, uma maior quantidade de adsorvato (CLARK, 2010).

Ademais, pode-se analisar que para 1,50 g de capim obteve-se uma considerável remoção do corante, porém como discutido, com baixo $q$. Já para 0,50 g o $q$ apresentou maiores valores pelo fato de azul de metileno ainda estar presente em grande quantidade na solução. Para 1,00 g de capim houve praticamente a mesmo percentual de remoção do corante com o $q$ mais alto, em relação a 1,50 g. Assim, pontuando estes fatores, determinou-se que nas condições aplicadas, a massa ideal de capim para se obter uma máxima adsorção é de 1,0 g.

A Tabela 3 demonstra os resultados dos ensaios de $\mathrm{pH}$ utilizando a solução de 0,25 $\mathrm{g} / \mathrm{L}$ de $\mathrm{AM}$ e $1,0 \mathrm{~g}$ de capim. Observa-se que os resultados obtidos de $q$ e percentual de remoção apresentam valores muito próximos e portanto pode-se concluir que o $\mathrm{pH}$ tem baixa influência na adsorção de AM em capim-annoni-2.

Tabela 3 - Influência do pH na adsorção de azul de metileno

\begin{tabular}{|c|c|c|}
\hline $\mathrm{pH}$ & $\mathrm{q}(\mathrm{mg} / \mathrm{g})$ & \% Remoção \\
\hline \hline 10 & $10,30 \pm 0,0482$ & $83,32 \pm 0,7759$ \\
\hline 7 & $10,13 \pm 0,0973$ & $81,21 \pm 1,0800$ \\
\hline 4 & $10,20 \pm 0,1232$ & $82,15 \pm 1,3839$ \\
\hline
\end{tabular}

O mesmo comportamento também foi observado por autores que estudaram a adsorção de diferentes corantes utilizando variados biossorventes. Entre eles, destacam-se Bilgiç (2005) e Alves (2013), no estudo da adsorção de verde malaquita, Clark (2010), com a remoção de fenilalanina, e Filho (2015), com a adsorção de violeta cristal. 


\section{CONCLUSÃO}

Através dos estudos realizados neste trabalho, pode-se analisar se a planta capimannoni-2 possui capacidade adsortiva e em quais níveis das condições de operação (concentração do corante em solução, massa de adsorvente e o pH do meio), melhor responderiam à adsorção de AM na mesma. Em vista dos resultados, conclui-se que o capimannoni- 2 foi um bom adsorvente, apresentando em média $80 \%$ de remoção do corante em solução. De acordo com a relação balanceada entre a capacidade de adsorção e a porcentagem de remoção do processo, a melhor concentração de AM e massa de capim moído foram de $0,25 \mathrm{~g} / \mathrm{L}$ e $1,0 \mathrm{~g}$, respectivamente. Ademais, também pode-se averiguar que a variação do $\mathrm{pH}$ do meio possui uma baixa influência no processo de adsorção do caso estudado.

\section{REFERÊNCIAS}

ALVES, F. C. Estudo dos processos de adsorção utilizando argilas como adsorventes para remoção do corante verde malaquita. 107 f. Dissertação (Mestrado em Agroquímica). Universidade Federal de Lavras, Lavras, 2013.

BILGIÇ, C. Investigation of the factors affecting organic cation adsorption on some silicate minerals. Journal of Colloid and Interface Science, v. 281, p. 33-38, 2005.

BORGES, W. M. S.; Avaliação do potencial de carvões ativados (pó e briquetados) produzidos a partir de resíduos de madeira na.adsorção de poluentes. Dissertação de Pós-Graduação em Agroquímica, UFLA. Lavras, 2014.

CLARK, H. L. M. Remoção de fenilalanina por adsorvente produzido a partir da torta prensada de grãos defeituosos de café. 115 f. Dissertação (Mestrado em Ciência de Alimentos). Universidade Federal de Minas Gerais, Belo Horizonte, 2010.

CÓRDOVA, F.N.; SILVA, M.M. da; CÓRDOVA, P.P. Tratamento de efluentes industriais têxteis. 2010. 19f. Conclusão de Trabalho (Curso Técnico Em Meio Ambiente na disciplina de Sistemas de Tratamento de Águas e Resíduos) - Escola de Educação Básica Dr. Otto Feuerschuette, Capivari de Baixo, 2010.

DALLAGO, R.M.; SMANIOTTO, A.; OLIVEIRA, L.C.A. de. Resíduos sólidos de curtumes como adsorventes para a remoção de corantes em meio aquoso. Revista Química Nova, v. 28, n. 3, 2005 .

DEBRASSI, A.; LARGURA, M. C. T.; RODRIGUES, C. A. Adsorção do corante vermelho congo por derivados da o-carboximetilquitosana hidrofobicamente modificados. Química Nova, v. 34, n. 5, p. 764-770, 2011.

FILHO, A. T. S. Remoção do violeta cristal por adsorção utilizando carvão ativado. 2015. 24 f. Monografia (Graduação em Engenharia Química) - Escola de Engenharia. Universidade Federal do Rio Grande do Sul, Porto Alegre, 2015. 
GOULART, I.C.G.R. et al. Controle de capim-annoni-2 (ERAGROSTIS PLANA) com herbicidas pré-emergentes em associação com diferentes métodos de manejo do campo nativo. Planta Daninha, Viçosa-MG, v. 27, n. 1, p. 181-190, 2009.

KIMURA, I. Y. Remoção de corantes reativos contendo grupos vinilsulfona e triazina por adsorção e coagulação/floculação com quitosana. Tese de Doutorado em Química. Departamento de Química. Universidade Federal de Santa Catarina, Florianópolis, 2001.

KLEIN, A.P.P. Estudo fitoquímico das folhas de capim annoni-2 (ERAGROSTIS PLANA NEES) coletadas no inverno e verão. PPG-TPQB/UTFPR, Pato Branco-PR, 103p. (dissertação de mestrado), 2015.

MEDEIROS, R.B.; FOCHT, T. Invasão, prevenção, controle e utilização do capim-annoni-2 (Eragrostis plana Nees) no Rio Grande do Sul, Brasil, 2007.

MITTAL, A.; MITTAL, J.; MALVIYA, A.; KAUR, D.; GUPTA, V.K. Adsorption of hazardous dye crystal violet from wastewater by waste materials. Journal of Colloidand Interface Science, v. 343, p. 463-473, 2010.

NASCIMENTO, R. F. do; et al. Adsorção: aspectos teóricos e aplicações ambientais. Fortaleza: Imprensa Universitária, 2014.

PERUZZO, L. C. Influência de agentes auxiliares na adsorção de corantes de efluentes da indústria têxtil em colunas de leito fixo. Dissertação de Mestrado em Engenharia Química. Universidade Federal de Santa Catarina, Florianópolis, 2003.

REIS, J. C. L. Capim annoni-2: Origem, Morfologia, Características, Disseminação. In: REUNIÃO REGIONAL DE AVALIAÇÃO DE PESQUISA COM ANNONI-2, Anais. Bagé: EMBRAPACPPSUL, 1993. p. 5-23. EMBRAPA-CPPSUL. Documentos, 7. 1991.

\section{AGRADECIMENTOS}

Os autores agradecem à UNIPAMPA, ao curso de Engenharia Química, aos servidores rensponsáveis pelos laboratórios e ao Programa de Educação Tutorial (PET) pela oportunidade de realizar este trabalho. 